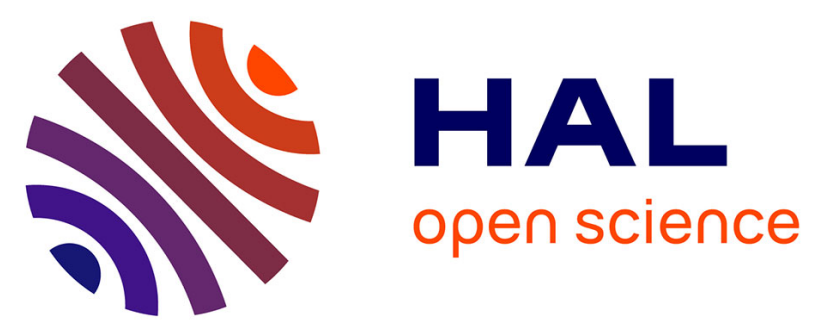

\title{
Histologic and histomorphometric evaluation of new zirconia-based ceramic dental implants: a preclinical study in dogs
}

Doriane Chacun, Arnaud Lafon, Nicolas Courtois, Helen Reveron, Jérôme Chevalier, Patrice Margossian, Antoine Alves, Kerstin Gritsch, Brigitte Grosgogeat

\section{To cite this version:}

Doriane Chacun, Arnaud Lafon, Nicolas Courtois, Helen Reveron, Jérôme Chevalier, et al.. Histologic and histomorphometric evaluation of new zirconia-based ceramic dental implants: a preclinical study in dogs. Dental Materials, 2021, 37 (9), pp.1377-1389. 10.1016/j.dental.2021.06.010 . hal-03439337

\section{HAL Id: hal-03439337 https://hal.science/hal-03439337}

Submitted on 22 Nov 2021

HAL is a multi-disciplinary open access archive for the deposit and dissemination of scientific research documents, whether they are published or not. The documents may come from teaching and research institutions in France or abroad, or from public or private research centers.
L'archive ouverte pluridisciplinaire HAL, est destinée au dépôt et à la diffusion de documents scientifiques de niveau recherche, publiés ou non, émanant des établissements d'enseignement et de recherche français ou étrangers, des laboratoires publics ou privés. 


\title{
Histologic and histomorphometric evaluation of new zirconia-based ceramic dental implants: a preclinical study in dogs
}

\author{
Doriane CHACUN ${ }^{a, b}$, Arnaud LAFON ${ }^{a, b}$, Nicolas COURTOISc, Helen REVERON ${ }^{d}$, Jérôme \\ CHEVALIER, Patrice MARGOSSIANe, Antoine ALVESf, Kerstin GRITSCH ${ }^{a, b}$ and \\ Brigitte GROSGOGEAT ${ }^{a, b}$
}

a Université de Lyon, Lyon, Université Lyon 1, Laboratoire des Multimatériaux et Interfaces UMR CNRS 5615, Faculté d'Odontologie, France

b Hospices Civils de Lyon, Pôle d'Odontologie, Lyon, France

c Anthogyr, 74700 Sallanches, France

d Université de Lyon, INSA-Lyon, UMR CNRS 5510 MATEIS, 20 Avenue AlbertEinstein, 69621 Villeurbanne Cedex, France

e Dental surgeon, PhD, exclusive private practice of Implantology and Periodontology, Marseille, France,

f NAMSA, 38670 Chasse-sur-Rhône, France

Corresponding author, Brigitte GROSGOGEAT; E-Mail: brigitte.grosgogeat@univ-lyon1.fr

ABSTRACT

Objective. Healing of soft tissues and improvement of aesthetics have become major research objectives in implantology and renewed the interest for ceramics implants. The aim of this study wás to evaluate the pre-clinical performance of screw-shaped sandblasted-etched implants processed from an innovative zirconia-based ceramic composite, in comparison to titanium.

Methods. Twenty-four ceramic and twenty-four titanium screw-shaped sandblasted-etched dental implants were tested in a splitmouth design in six Beagle dogs. Surface topographies were investigated by confocal microscopy. Local tissue effects were evaluated at 4 and 13 weeks after implantation through histology. An ANOVA statistical analysis $(5 \%$ risk; p<0.05) was performed to compare peri-implant quantitative histomorphometric parameters on buccal and lingual sides, including Bone to Implant Contact (BIC) among test groups and time-periods.

Results. Titanium and ceramic implants presented respectively moderate and minimal roughness. After 4 and 13 weeks, ceramic implants showed an inflammatory tissue response close to titanium implants. At both period of time there was no significant difference between the titanium and ceramic groups in terms of BIC values (mean \pm SD) at the lingual or buccal sides or when combining buccal + lingual BIC values (respectively for titanium and ceramic, $68.4 \pm 14.7 \%$ and $75.0 \pm 13.5 \%$ at 4 weeks, and $92.0 \pm 8.6 \%$ and $86.1 \pm 13.8 \%$ at 13 weeks).

Significance. Within the limits of the present study, it can be concluded that newly developed zirconia-based ceramic composite dental implants have similar biocompatibility and osseointegration to those observed in titanium implants These pre-clinical results corroborate the potential for the use of these new zirconia-based ceramics in oral implantology.

Keywords:

Osseointegration

Dental implant

Zirconia

Ce-TZP

Alumina

Bone to implant contact (BIC) 
Histomorphometric evaluation Animal study

\section{Introduction}

Half a century ago, the combination of its favorable mechanical properties and osseointegration ability rapidly installed titanium as the gold standard in oral implantology [1], although some alternative materials like ceramics were already proposed [2]. However, regarding the aesthetic appearance, the grey color of the titanium might pose a problem in the areas of the upper anterior and premolar teeth, especially if the gingival phenotype is thin, because the implant may be visible behind these tissues. Aesthetic improvements becoming a major research goal in dental implantology, there are has recently a renewed interest for ceramics implants. Ceramics are also known to represent a very high resistance to corrosion. This led to the selection of 3 mol\% Yttria-doped Tetragonal Zirconia Polycrystals (3Y-TZP) because of its outstanding mechanical properties, mainly related to phase transformation toughening mechanism [3].

Despite the outstanding strength of 3Y-TZP (usually $>1 \mathrm{GPa}$ ), this material has only moderate toughness $(5-8 \mathrm{MPa} \sqrt{\mathrm{m}})$ and present a sensitivity to the presence of flaws, as is the case for most ceramic materials. Furthermore, depending on manufacturing process [4] or surface modifications [5], 3Y-TZP may be sensitive to Low Temperature Degradation (LTD) in aqueous environment. Even if there is so far no clinical evidence LTD could have led to premature failure of zirconia dental implants and the risk partially covered by current standards, this is one additional concern to the risk of brittle failure [6]. The fracture rate related to the use of 3Y-TZP is low, which shows that the material present a credible alternative to titanium, but some reports of fractures of one-piece 3Y-TZP implants in clinical studies [7-9] may motivate the search for alternative, tougher, ceramic materials. Tri-phasic oxide materials based on Ceria-doped zirconia (Ce-TZP) were developed recently to be more LTD resistant and tougher than 3Y-TZP [10]. In particular, these new ceria-based zirconia composites were found to exhibit a considerable crack resistance and a significant ductility before failure thanks to a process of transformation-induced plasticity $[10,11]$. The very high flaw resistance of these Ce-TZP-based composites allows to increase the roughness, for example to improve the osseointegration, without compromising the mechanical behavior of the implant, in contrast to what is generally observed in 3Y-TZP implants [11].

It is already established that zirconia and alumina-based composites are highly biocompatible and can be used as dental devices, but data related to the osseointegration of these new tri-phasic Ce-TZP based materials in a relevant animal model are lacking. To the best of our knowledge only one study has investigated this material, but in a femur rat model and using small rods that were pushed-in [12]. The aim of the present study was therefore to assess through histologic and histomorphometric evaluations the pre-clinical performance of screw-shaped sandblasted-etched Ce-TZP-based-ceramic implants in comparison to titanium, in an established canine jaw model

\section{Materials and methods}

\subsection{Ce-TZP-based composite characterization}

The process of the implant prototypes and the main features of the developed ceramic composite were already described in details in [11]. In brief, the composite exhibits a Ceria-doped based zirconia as the main phase (86 vol.\% of the composite), and Alumina and Strontium (Sr) aluminate as the second phases (both 8 vol.\% of the composite). A mixture of the three ceramic powders is granulated by spray drying, cold-isostatically pressed ( $300 \mathrm{MPa}$ ), sintered at $1450^{\circ} \mathrm{C}$ for 1 hour and then machined in the sintered state to final shape. 
Microstructural features and surface topography of ceramics were examined by SEM (Zeiss Supra 55, Oberkochen, Germany). The average grain size of zirconia and alumina was estimated from the linear intercept method using 1.56 as correction factor. To evaluate the size of elongated Sr-aluminate grains, the maximum length and width were measured. Density was determined by Archimedes' method using distilled water according to the C373-88(2006) ASTM standard. The relative density of the Ce$\mathrm{TZP} / \mathrm{Al}_{2} \mathrm{O}_{3} / \mathrm{SrAl}_{12} \mathrm{O}_{19}$ materials was estimated.

Mechanical properties were characterized as recommended in 6872(2008) ISO standard, by four-point bending (4PB). The strength $\left(\sigma_{r}\right)$ and Weibull modulus $(\mathrm{m})$ of Ce-TZP-based composites were measured in four-point bending using 20 rectangular bars ( $4 \mathrm{~mm} \times 3 \mathrm{~mm} \times 40 \mathrm{~mm})$ with outer and inner spans' lengths of 35 and $10 \mathrm{~mm}$, respectively. The surfaces of the bars were polished down to $16 \mu \mathrm{m}$ before testing as recommended in the ISO standard. A universal hydraulic testing machine (Instron 8502, Nordwood, USA) was used and a cross-head speed of $1 \mathrm{~mm} / \mathrm{min}$ applied. In order to study the effect of surface treatments (alumina-blasting and chemical etching), 13 additional rectangular bars were also blasted and etched following the same procedure applied in implants, then tested in 4PB under the same conditions described above. Unbiased values of the Weibull modulus $(\mathrm{m})$, and the characteristic strength $\left(\sigma_{0}\right.$ which is the stress corresponding to $62.3 \%$ fracture probability), with their $95 \%$ confidence limits (CL) were calculated according to the procedure proposed by Davies [13]. To evaluate the toughness, the SingleEdge-Notch-Bending (SENB) method was performed on notched rectangular bars ( $4 \mathrm{~mm} \times 2 \mathrm{~mm} \times 25 \mathrm{~mm}$ ) tested in $4 \mathrm{~PB}$ at a crosshead speed of $0.5 \mathrm{~mm} / \mathrm{min}$, with outer and inner spans' lengths of 21 and $10 \mathrm{~mm}$, respectively.

\subsection{Implants}

\subsubsection{Design and surface treatments}

Anthogyr (Anthogyr SAS, Sallanches, France) provided the implants evaluated in the present study (Fig. 1). Both control (titanium-based) and test implants (ceramic-based) were screw-shaped and produced in reduced dimensions for implantation in dogs: $2.8 \mathrm{~mm}$ diameter, total length $9.5 \mathrm{~mm}$, endosseous length $8 \mathrm{~mm}$. The control groups consisted of machined surgical grade titanium alloy implants (Ti6Al4V-ELI according to ASTM F136 and IS05832-3). Test implants were machined from ceramic composite bars made of $\mathrm{CeO}_{2}$-doped zirconia containing alumina and strontium aluminate as secondary phases (Ce$\mathrm{TZP} / \mathrm{Al}_{2} \mathrm{O}_{3} / \mathrm{SrAl}_{12} \mathrm{O}_{19}$ ). Titanium-based machined implant surface was blasted using a mixture of hydroxyapatite and tricalcium phosphate particles (Anthogyr Axiom® implants procedure) and then immersed in a nitric acid bath. Ceramic implants were blasted with $150 \mu \mathrm{m}$ alumina particles (3.5 bars) and then immersed in an acid solution (7\% hydrofluoric and $43 \%$ nitric acids, 3 hours). Both implants groups were subsequently rinsed, decontaminated, and gamma-ray-sterilized. Throughout this study, the control group refers to titanium-based implants and the test group to ceramic ones. 

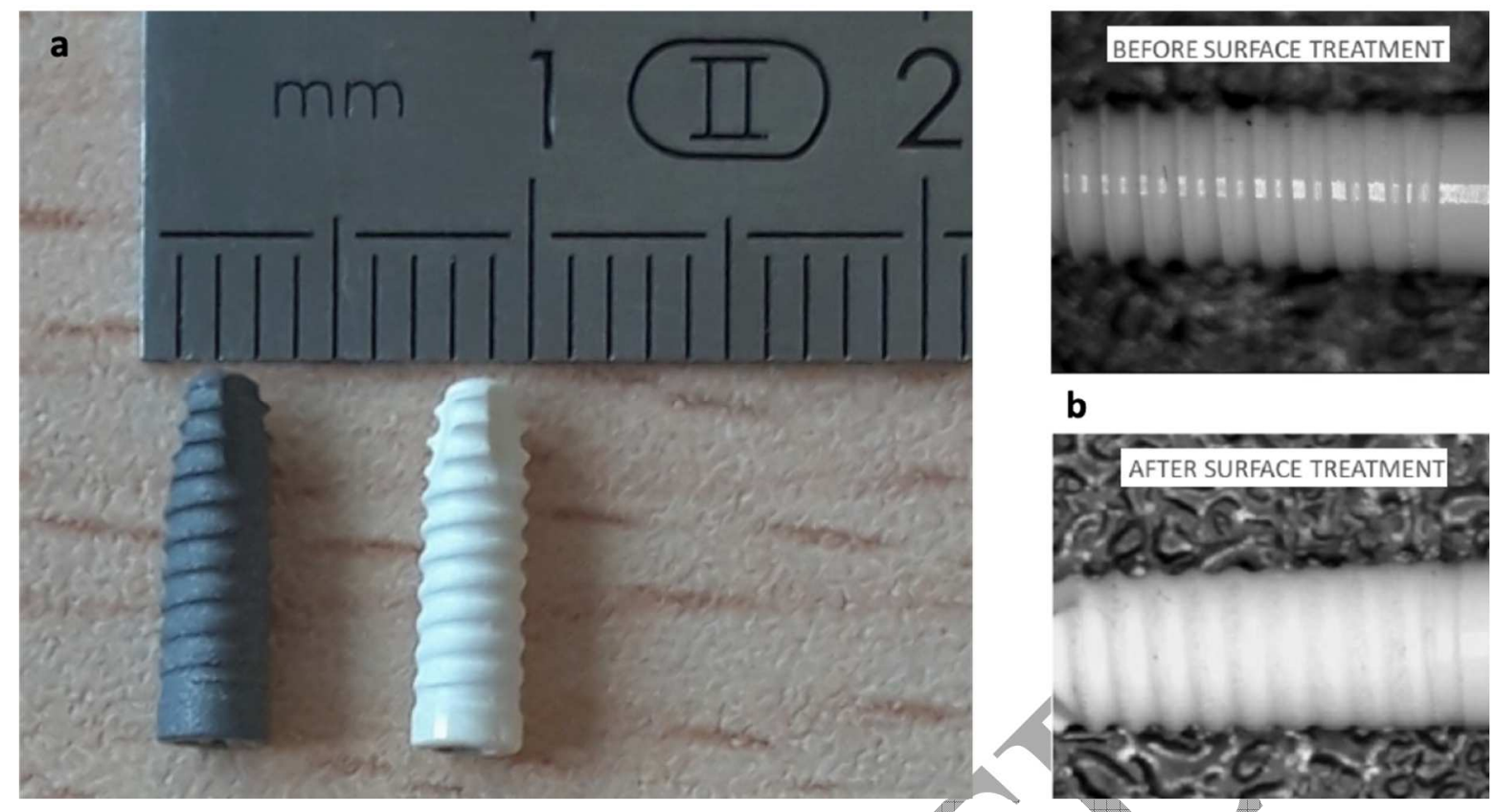

b

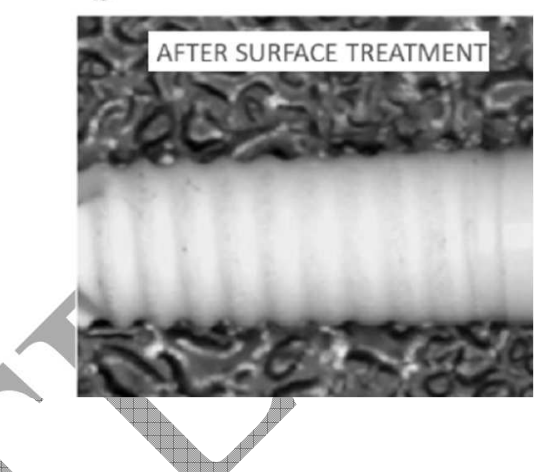

Fig. 1 - (a) Titanium-based implant (left) and Ce-TZP-based ceramic implant (right) as-machined, sandblasted and chemically-etched. (b) Ce-TZP-based ceramic machined implant (top) compared to a machined, blasted and acid etched implant (bottom).

\subsubsection{Topographic characterization}

According to the guidelines defined by Wennerberg and Albrektsson [14], a 3D non-contact measurement of the surface topography was performed on both implant groups and in three different areas, using a S-Neox profilometer (Sensofar, Terrassa, Spain) in vertical scanning interferometry mode with $20 \mathrm{x}$ objective. The surface analyzed was at least of $250 \times 450 \mu \mathrm{m} 2$ and up to $800 \times 600 \mu \mathrm{m} 2$ depending on the area of interest. A robust Gaussian filter $50 \mu \mathrm{mx} 50 \mu \mathrm{m}$ was applied and the mean \pm standard deviation (SD) of different surface texture parameters (Sa/Arithmetical mean height, Sdr/Developed Interfacial Area Ratio and Sds/ Summit Density) were computed from mine measurements taken in 3 implants and 3 different zones for each (MountainsMap, Digital Surf, Besançon, France). The classification proposed by Albrektsson and Wennerberg [15] was applied to qualify the surfaces of titanium-based and Ce-TZP-based implants. The roughness (Ra/ Aritmethical mean deviation) was also measured on a single area by contact profilometry (SurfTest; Mitutoyo, Tokyo, Japan) in both, metallic and ceramic implants.

2.3. Animals

The animal study was conducted in accordance with the Organisation for Economic Cooperation and Development (OECD) Good Laboratory Practice regulations, ENV/MC/CHEM (98) 17 and with the United States Food and Drug Administration (FDA) Good Laboratory Practice regulations, 21 CFR 58, in an accredited facility (NAMSA, Chasse-sur-Rhône, France) registered at the French department of agriculture for animal housing, care, and investigations (approval number: D3808710001). The protocol of the present study was established by NAMSA before carrying out this experiment and consistent with the requirements of the European legislation for the protection of animals used for scientific purposes (Directive 2010/63/EU); and in accordance with the ARRIVE guidelines [16]. The ethical approval for this project was obtained from the French Ministry of Higher Education, Research and Innovation (project number 05285.06.A). 
Six skeletally mature Beagle male dogs (HsdRcc:DOBE) were involved in the present study. The animals were adults (at least 12 months old), healthy, previously unused and weighed a mean $\pm S D$ 14.4 $\pm 0.3 \mathrm{~kg}$. Following implantation, the dogs were individually housed in cages for approximately two weeks (until complete wound healing), then housed in groups, up to the end of the study under laboratory conditions (humidity and temperature recorded daily). The temperature was maintained between 15 and $21^{\circ} \mathrm{C}$. The artificial light cycle was controlled using an automatic timer (12h light, $12 \mathrm{~h}$ dark). A commercially available diet (SAFE Complete Care Competence, Augy, France) was provided twice daily. The dogs were acclimated to a soft diet before surgery and fed only with a soft diet after surgery. Potable water was delivered ad libitum.

\subsection{Surgical procedure}

The study plan included: teeth scaling, dental extractions, and implantations, all under anesthesia, as well as necropsy at 4 or 13 weeks after implantation. Nine or 10 days before teeth extraction a full-mouth scaling was performed on each dog, using an ultrasonic device. The second to fourth pre-molars (P2, P3, P4) and first molar (M1) in the right and left mandibles of the six dogs were extracted in a non-traumatic procedure using open flap surgery and root separation using a Zekria burr.

Ten weeks after dental extractions, the implantation procedure was performed by an experimented surgeon under aseptic conditions. A full thickness flap was retracted and four osteotomies were created in each hemi-mandible, by three steps of drilling using a marking drill, a $2 \mathrm{~mm}$ drill and a $2.6 \mathrm{~mm}$ drill up to $10 \mathrm{~mm}$ deep, under extensive rinsing with saline. A tapping step, with a $2.8 \mathrm{~mm}$ tap of the surgical kit, was added to ease implantation procedure. Test and control implants were inserted on either side of the mandible $(\mathrm{n}=4 \times 2)$ with an inter-implant distance of $5 \mathrm{~mm}$, according to a split-mouth design (Fig. 2) pre-defined in the protocol. The sites were allocated by blocks: each anatomical location received balanced numbers of test and control implants, and they were administered in each animal to minimize interindividual bias. In this approach, sites were considered as independent even in a single animal.

Maximal insertion torques indicated by the surgical motor (Implanteo® LED; Anthogyr, Sallanches, France) were recorded for each implant. The gingival flap was closed with absorbable thread (Monocryl 5.0; Ethicon Inc., Somerville, MA, USA) and covered the implants. Animals were fully monitored for heart pulse, breathing frequency, oxygen saturation and body temperature during surgery.

The following care was administered. Local disinfection: the mouth was sanitized with chlorhexidine (Cooper, Melun, France) before and after teeth scaling, before and after each surgery, and on the sites once a day until wound healing was complete and suture removed. Antimicrobial prophylaxis: spiramycin and metronidazole (Buccoval@ petit chien; Sogeval, Louverné, France) were administered per os one day before teeth scaling and then daily until complete wound healing after teeth extraction. The treatment was renewed one day before implantation and was given daily until complete healing of the wound and suture removal. Anti-inflammatory drugs: carprofen (Rimadyl®; Zoetis, Madison, WI, USA) was administered subcutaneous before teeth extraction and implantation, and carprofen (Carprodyl@; Ceva, Libourne, France) was administered daily per os for five days following each surgery. Analgesia: buprenorphine (Buprecare ${ }^{\circledR}$; Axience, Pantin, France) was injected at the end of the extraction day and once the first day following surgery. This treatment was renewed at the end of the implantation day, then twice a day for two days. After complete healing of the gingival wounds (approximately two weeks) the sutures are removed and the sites are cleaned with chlorhexidine (Cooper).

The animals were euthanized at 4 weeks (three dogs) and 13 weeks (three dogs) after implantation, with a lethal intravenous injection of pentobarbital (Dolethal@; Vetoquinol, Magny-Vernois, France) after intramuscular injection of tiletamine-zolazepam (Zoletil®; Virbac, Carros, France) and subcutaneous injection of buprenorphine (Buprecare ${ }^{\circledR}$; Axience). Radiophotographs of 


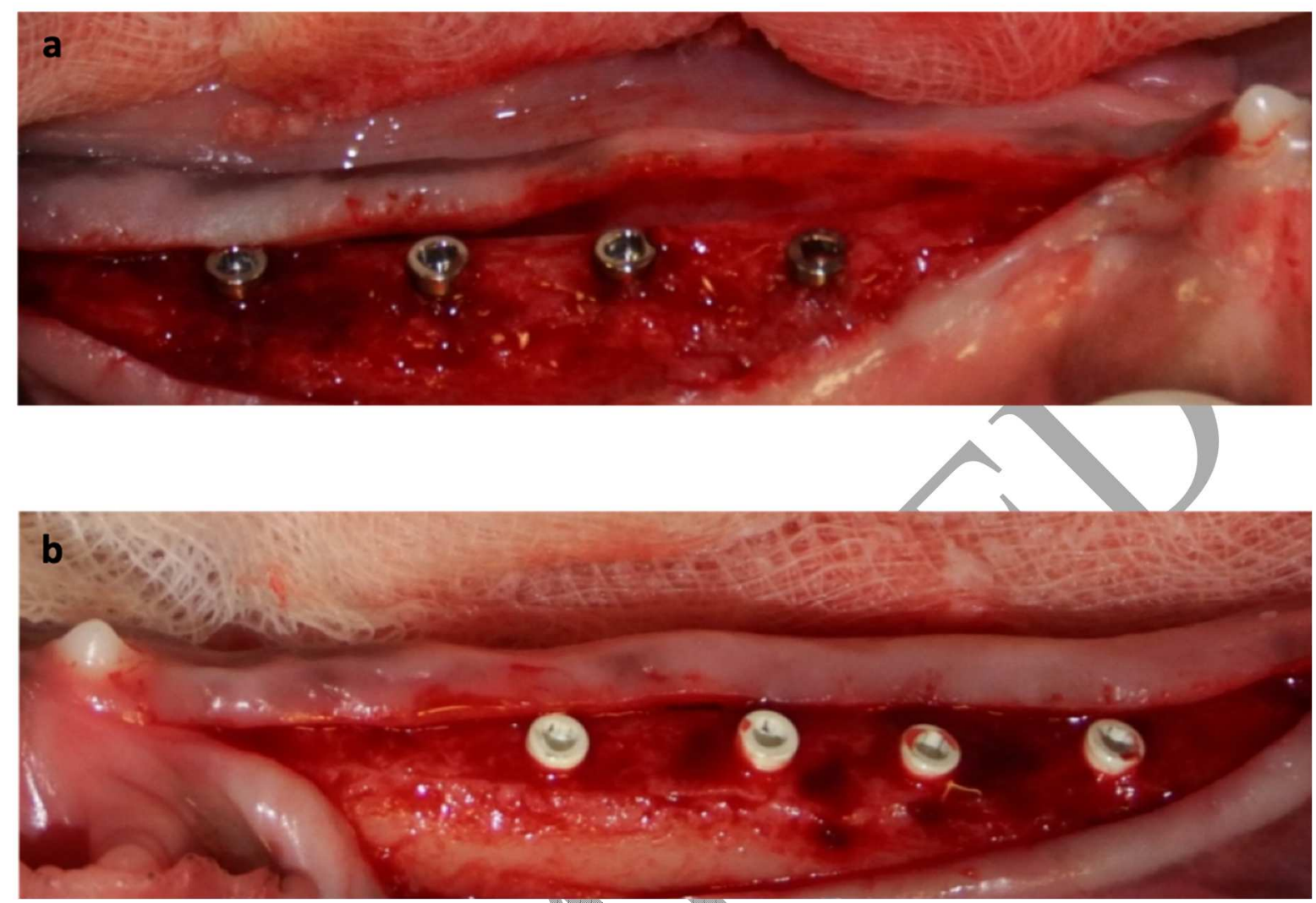

Fig. 2 - Control titanium (a) and test Ce-TZP composite ceramic (b) implants placed in the dog mandibles.

\subsection{Histologic preparation and histopathologic evaluations}

After fixation in 10\% NBF the hemi-mandibles were dissected into individual blocks with a band saw (one block per site). The 48 sites were oriented based on the buccal, lingual, mesial and distal sides, and fixed again in $10 \%$ NBF. After complete fixation, the sites were dehydrated in alcohol solutions of increasing concentration, cleared in xylene, and embedded in polymethylmethacrylate (PMMA). One central frontal bucco-lingual section (approximately 40 $\mu$ m thickness) was obtained by microcutting and grinding technique (Exakt Technologies Inc, Oklahoma City, OK, USA). The buccal and lingual orientations, as well as the mesial and distal orientations, were identified on the slides. The sections were stained with modified paragon for qualitative, semi-quantitative and quantitative analysis.

\subsubsection{Local tissue effects: qualitative and semi-quantitative evaluations}

The local tissue effects after implantation at 4 and 13 weeks of the Ce-TZP-based and Titanium-based control implants were examined by microscopy and investigated by an experienced anatomo-pathologist through the evaluation and the scoring in severity of tissue damage (using a five point system : minimal, slight, moderate, marked or severe, according to the rules of General Pathology), cellular inflammatory parameters, repair phase of inflammation, fatty infiltrate parameters, and other parameters according to ISO 10993-6:2016: (Biological evaluation of medical devices - Part 6: test for local effects after implantation [17]). A mean irritation score was calculated using individual irritation scores for each implant. The reactivity ranking was then calculated by subtracting the mean irritation score (rounded to the nearest 0.1 ) of the control implant from the mean irritation score (rounded to the nearest 0.1 ) of the ceramic implant; this reflects the inflammatory intensity and the local 
tissue effects for the test implant. A negative difference was recorded as zero; the reaction to the test implant was graded a null to minimal reaction ( 0.0 to 2.9 ), slight reaction (3.0 to 8.9), moderate reaction (9.0 to 15.0 ), or severe reaction ( $\geq 15.1$ ).

Comparisons between control (Titanium-based) and test (Ce-TZP-based) implant were performed at 4 and 13 weeks (n=12 implants per group and per time period) and allowed to judge about the biocompatibility of the test implants.

\subsubsection{Histomorphometric analysis: quantitative evaluation}

The quantitative performance of the test and control implants were evaluated through histomorphometric analysis. Each section was scanned using a light/fluorescence microscope (AxioScan Z1, x20; Carl Zeiss, Jena, Germany) and analyzed with a color image analyzing system (CaloPix v3.2.0; Tribvn Healthcare, Châtillon, France) to perform a semi-automatic analysis. Two standardized Regions of Interest (ROI) were defined for each longitudinal section by the pathologist: one ROI was positioned on the buccal side (ROI B) and the other on the lingual side (ROI L; Fig. 3). The dimension of the ROI was 6000x800 $\mu$, starting at the first coronal threads. The length may vary in absence of threads at the apical portion of the dental implant, where smooth surfaces are observed. The quantitative analysis was performed to assess the proportion of the following parameters. Bone to Implant Contact (BIC): percentage of the dental implant perimeter in direct contact with the mineralized bone tissue (primary endpoint); bone area density (also called bone density): percentage of ROI occupied by the bone tissue in terms of area surface; fibrous area density (also called fibrous density): percentage of the ROI occupied by the fibrous tissue in terms of surface area; bone marrow density: percentage of the surface of the ROIs occupied by bone marrow.

\subsection{Statistical analysis}

Data are expressed as mean \pm standard deviation (SD). The histomorphometric individual data in percentages were calculated based on the histomorphometric individual data rounded to $0.1 \mathrm{~mm}$. Statistical analysis (ANOVA test 5\% alpha risk, statistical significance was set at $\mathrm{p}<0.05$ ) was conducted for the histomorphometric parameters with statistical software (SPSS; SPSS Inc., Chicago, IL, USA). Performance of the test implant was based on the quantitative histomorphometric evaluation of the BIC and the percentage of newly formed bone in the ROI.

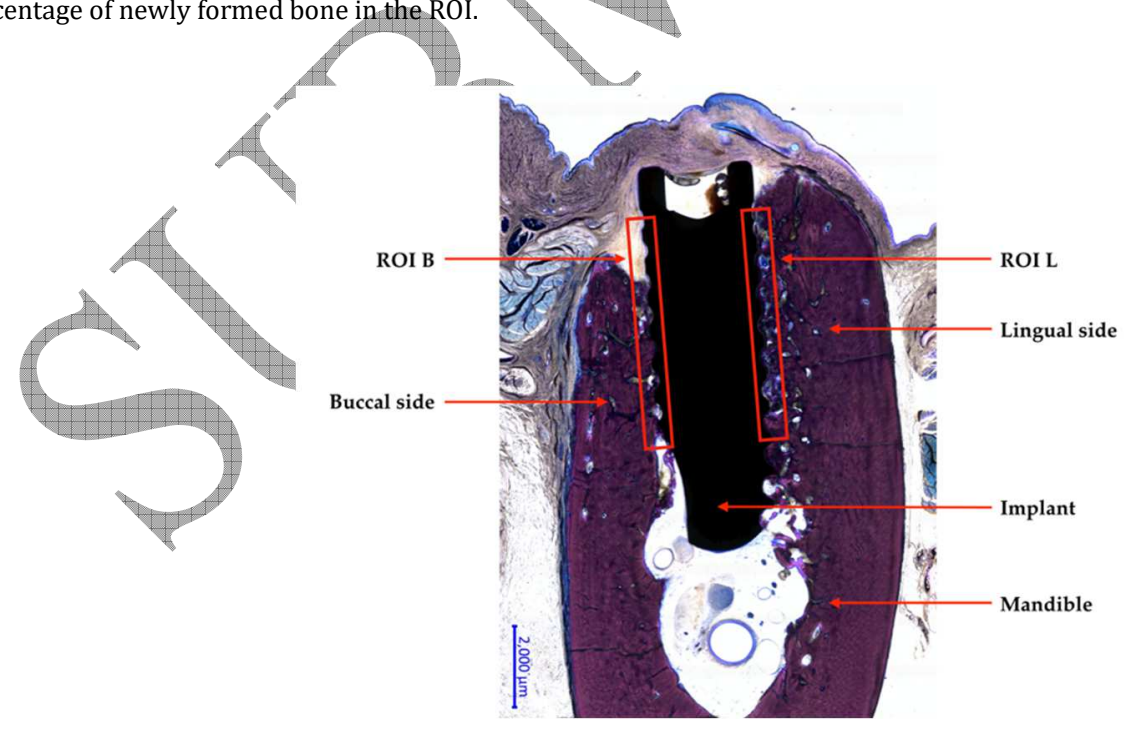

Fig. 3 - Illustration of a histological section showing the two bone-implant contact regions, ROI B and ROI L, analysed in this study.

\section{Results}




\subsection{Ce-TZP-based composite characterization}

The microstructure obtained in Ce-TZP $/ \mathrm{Al}_{2} \mathrm{O}_{3} / \mathrm{SrAl}_{12} \mathrm{O}_{19}$ composites is shown in Fig. 4. It consists of zirconia grains (Ce-TZP) of $0.41 \pm 0.06 \mu \mathrm{m}$ (light grey grains), alumina grains $\left(\mathrm{Al}_{2} \mathrm{O}_{3}\right)$ of $0.34 \pm 0.03 \mu \mathrm{m}$ (dark grey, isotropic grains) and strontium aluminate platelets $\left(\mathrm{SrAl}_{12} \mathrm{O}_{19}\right)$ with a mean length of $1.81 \pm 0.22 \mu \mathrm{m}$ and an aspect ratio (length/width) of about $6 \pm 2 \mu \mathrm{m}$ (elongated grains). Composites reached $96.3 \%$ of the theoretical density.

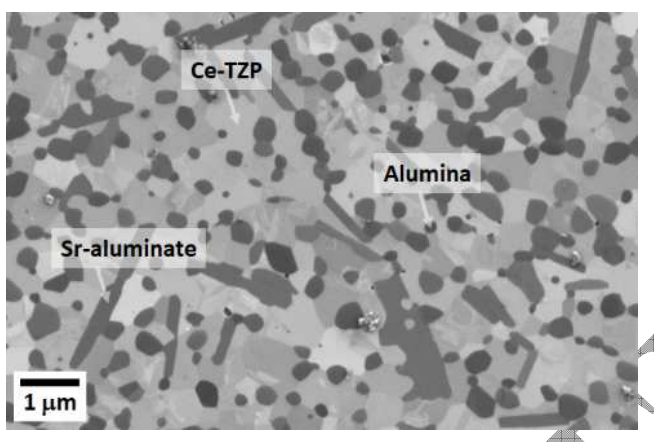

Fig. 4 - SEM characterization of Ce-TZP-based composite microstructure.

The toughness of the composite measured by SENB was $\mathrm{K}_{\mathrm{IC}}=7.2 \mathrm{MPa} \sqrt{\mathrm{m}}$. The 4 -point bending distribution is given in Fig.5. After a polishing down to 16 microns, the strength and Weibull modulus were respectively $\sigma_{\mathrm{r}}=730 \pm 45 \mathrm{MPa}$ and $\mathrm{m}=19$. After blasting and etching, the strength was not significantly affected and always remained higher than $700 \mathrm{MPa}\left(\sigma_{\mathrm{r}}=753 \pm 59 \mathrm{MPa}, \mathrm{m}=15\right)$.

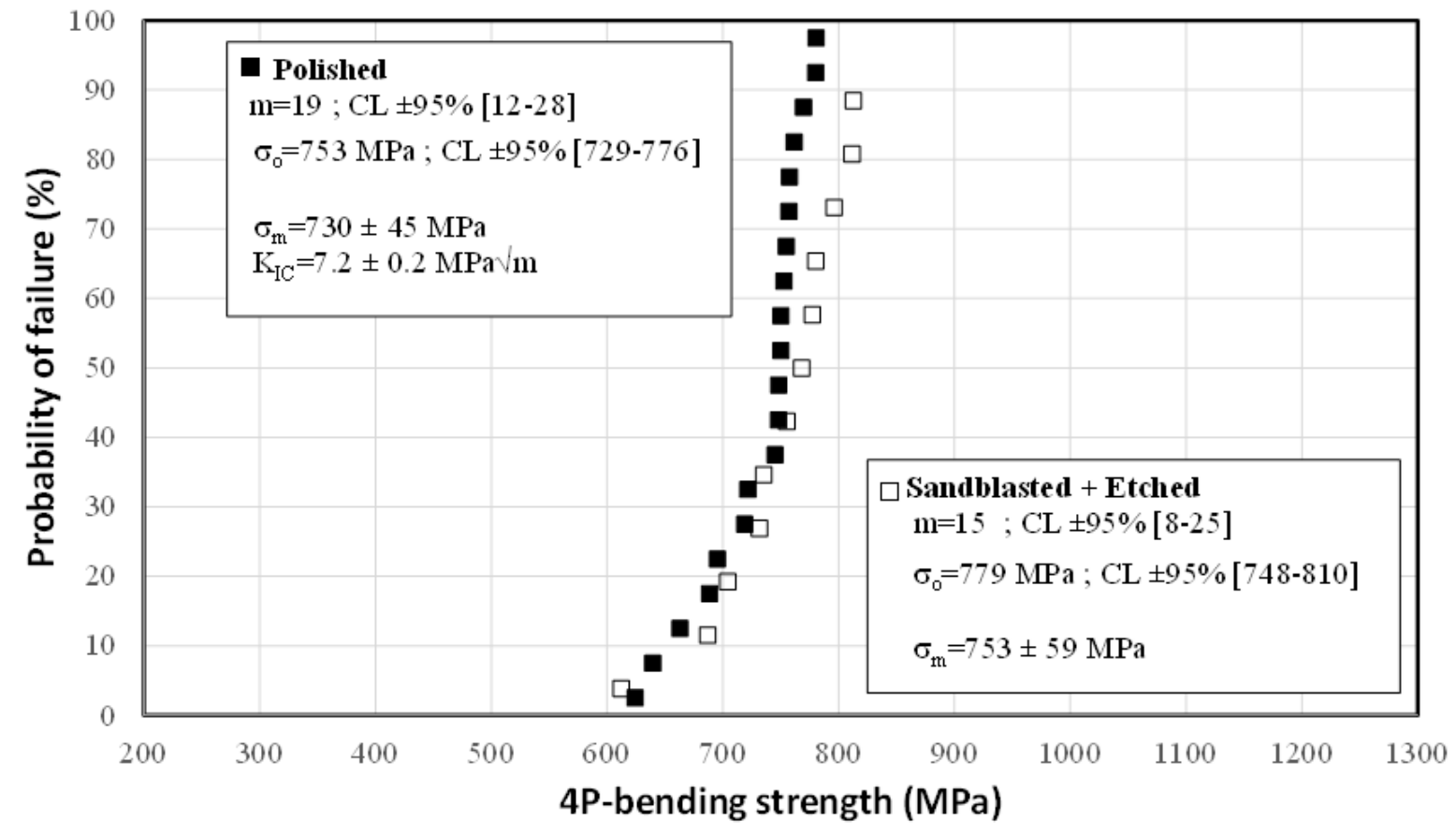

Fig. 5 - Weibull plot showing the probability of failure versus 4-point bending strength of Ce-TZP based composite materials. m: Weibull modulus, CL: confidence limit, $\sigma_{0}$ : characteristic strength, $\sigma_{\mathrm{m}}$ : mean strength. 


\subsection{Topographic characterization}

Ce-TZP-based machined surfaces after blasting and chemical etching treatments are shown in Fig. 6. Blasting lead to a roughness value (Ra) of $1.3 \mu \mathrm{m}$ that decreased to $1.0 \mu \mathrm{m}$ after the chemical treatment. Topographic features are homogenous over all modified zones.

The titanium-based implants used in the present study (control group) were rougher (Ra 1.5-2.0 $\mu \mathrm{m}$ ). This difference in roughness (see Table 1) is clearly visible in representative interferometric images (Fig. 7) where titanium presents larger and deeper surface features on average.
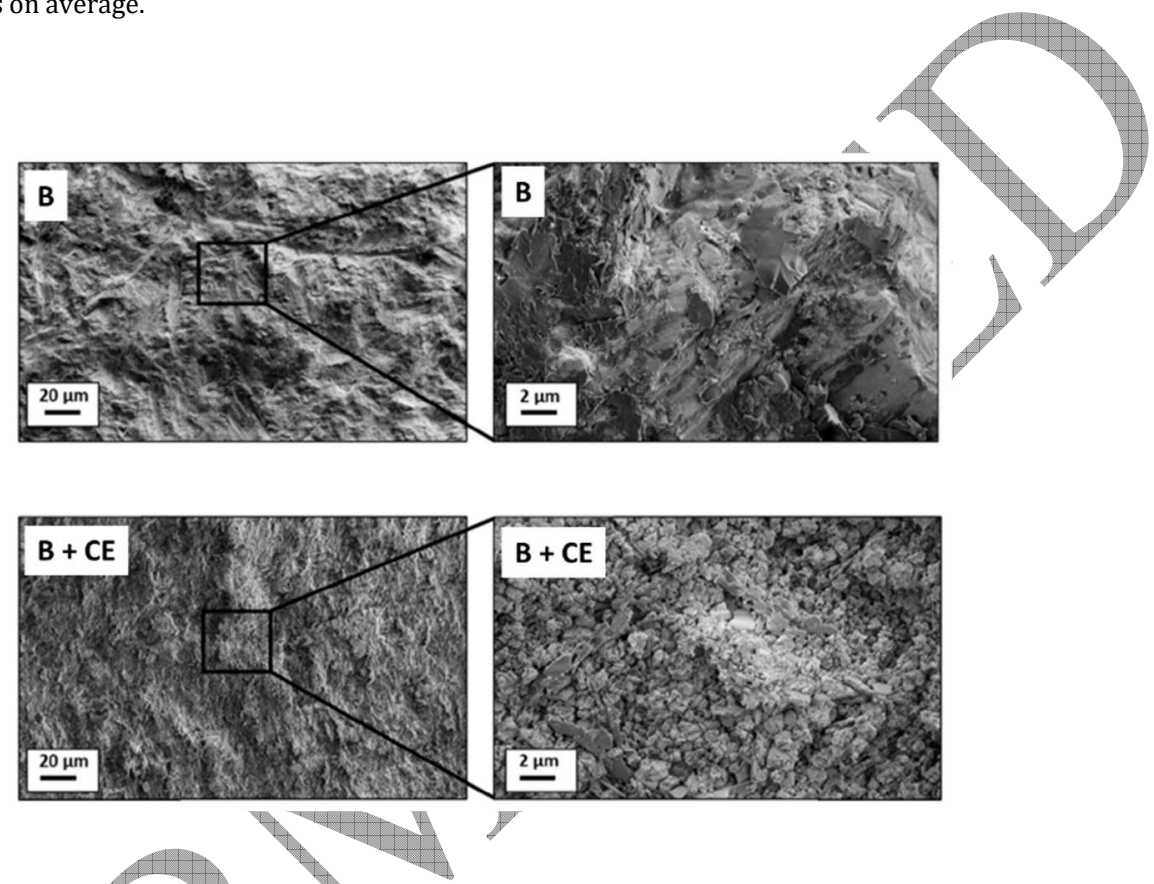

Fig. 6 - SEM characterization of Ce-TZP-based composite implant surfaces after blasting (B) and blasting + chemical etching (B+CE).

Table 1 - Mean of different roughness parameters* $( \pm S D)$ measured on both implant surfaces.

\begin{tabular}{|c|c|c|c|c|}
\hline 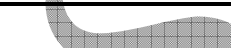 & $S a, \mu \mathrm{m}$ (SD) & Sdr, \% (SD) & Sds, $1 / \mu m^{2}$ (SD) & $\mathrm{Ra}, \mu \mathrm{m}$ (SD) \\
\hline Titanium & $1.21(0.12)$ & $19(5.2)$ & $0.012(0.004)$ & $1.5-2$ \\
\hline Ce-TZP composite & $0.68(0.21)$ & $11.7(6.6)$ & $0.024(0.009)$ & $\sim 1$ \\
\hline
\end{tabular}

* Sa, arithmetic mean deviation of the surface; Sdr, developed surface area ratio; Sds, density of summits; Ra, arithmetic mean deviation. 

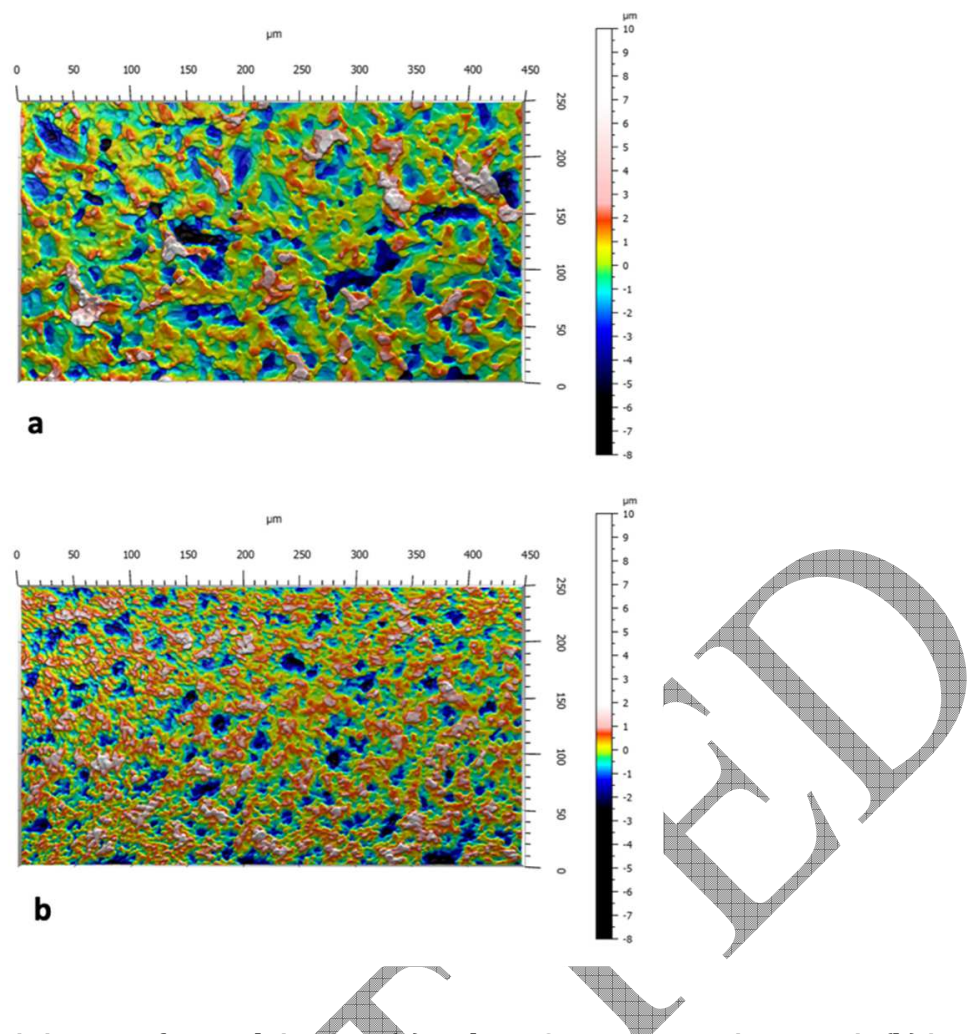

Fig. 7 - Representative interferometric images of control titanium (a) and test Ce-TZP composite ceramic (b) implants surfaces.

\subsection{Surgical procedure}

The mean final insertion torques $\pm S D$ were $15.7 \pm 7.9 \mathrm{~N} . \mathrm{cm}^{-1}$ for the control group and $14.9 \pm 4.1 \mathrm{~N} . \mathrm{cm}^{-1}$ for the test group. No major difficulty was encountered at implantation other than the extra-osseous coronal part of six ceramic implants broke during the implant insertion procedure when axis correction was performed by the surgeon. The breakage was in the outer part of the device (above the bone crest, not in contact with the evaluated bone); as this should have no impact on the histopathological analysis, the sites were not excluded. The sutures were removed after complete wound healing at day 15 or 16. Implant protrusions were observed in three dogs in both the control group (six sites) and test group (seven sites). At termination of these dogs (all at 13 weeks) all implants were visible through the gingiva that was very thin in the same three dogs. No other notable clinical observation was made. Otherwise, no difference in radiopacity was observed at 4 and 13 weeks compared to implantation.

\subsection{Histopathologic evaluation}

Forty-eight sites ( $\mathrm{n}=12$ implants per group and per time period) were submitted to histopathological analysis but only forty ( $n=10$ implants per group and per time period) were able to be analyzed due to handling errors.

\subsubsection{Local tissue effects : qualitative and semi-quantitative evaluations}

After 4 weeks of implantation, the test group induced a null to minimal reaction when compared to the control group (Table 2). Early evidence of secondary osseointegration was observed in both groups. Buccal bone loss was higher in the test group (one to three threads not covered by bone; Fig. 8b) compared to the control group (zero to two threads not covered by bone; Fig. 8a). 
After 13 weeks of implantation, the reaction of the test implant was graded slight (Table 2). Increased signs of osseointegration were observed in both groups but were scored very slightly lower in the test group. Buccal bone loss was higher in the test group (one to three threads not covered by bone; Fig. 8d) compared to the control group (zero to two threads not covered by bone; Fig. $8 c)$.

Table 2 - Histologic mean irritation scores and reactivity rankings.

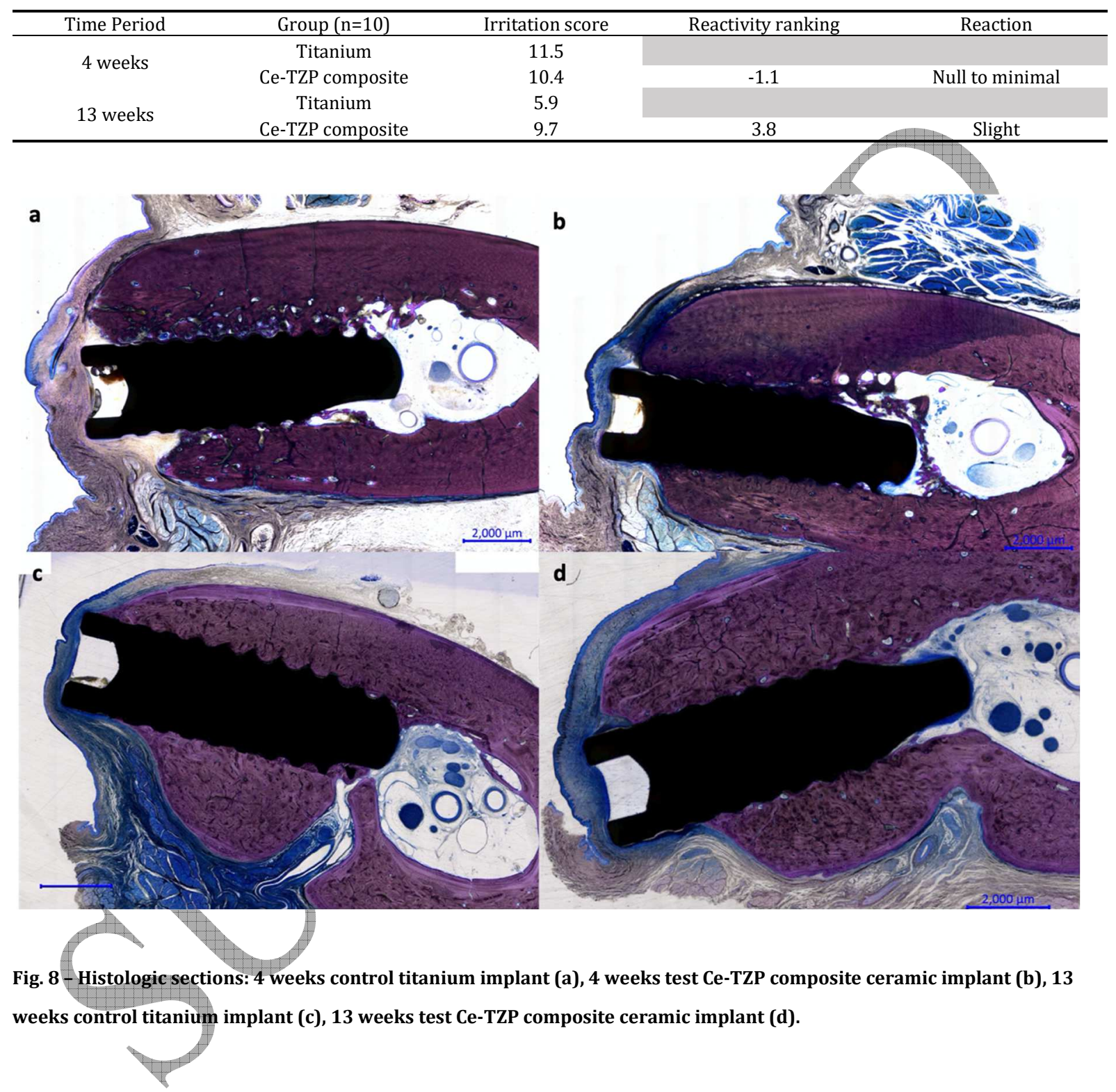

\subsubsection{Histomorphometric analysis: quantitative evaluation}

$\underline{\text { Bone to implant contact }}$

- Influence of the material: inter-group comparison

After 4 weeks, there was no significant difference between the two groups in terms of the mean BIC values at the lingual or buccal sides, or when combining buccal+lingual BIC values; after 13 weeks the same behavior was observed (Table 3). 
Table 3 - Histomorphometric results: mean values $( \pm \mathrm{SD})$

\begin{tabular}{|c|c|c|c|c|c|c|}
\hline $\begin{array}{l}\text { Time } \\
\text { period }\end{array}$ & & Group $(n=10)$ & BIC, \% (SD) & $\begin{array}{l}\text { Bone Density, \% } \\
\text { (SD) }\end{array}$ & $\begin{array}{c}\text { Fibrous } \\
\text { Density, \% } \\
\text { (SD) }\end{array}$ & $\begin{array}{c}\text { Bone Marrow } \\
\text { Density, \% (SD) }\end{array}$ \\
\hline \multirow{6}{*}{4 weeks } & \multirow{3}{*}{ Titanium } & Lingual $n=10$ & $64.6(16.8)^{c}$ & $72.6(10.8)^{* * *_{c}}$ & $9.7(4.9)^{* * c}$ & $17.7(10.1)^{\mathrm{c}}$ \\
\hline & & Buccal $n=10$ & $73.6(9.4)^{\mathrm{b}}$ & $63.3(9.1)^{\mathrm{b}}$ & $8.8(4.0)$ & $28.0(7.4)^{c}$ \\
\hline & & Buccal+Lingual $n=10$ & $68.4(14.7)^{c}$ & $67.5(11.4)^{\mathrm{c}}$ & $9.0(4.7)^{* * * a}$ & $23.5(11.0)^{\mathrm{c}}$ \\
\hline & \multirow{3}{*}{$\begin{array}{c}\text { Ce-TZP } \\
\text { composite }\end{array}$} & Lingual $\mathrm{n}=10$ & $79.3(12.7)^{\mathrm{b}}$ & $85.7(6.9)^{* * b}$ & $4.0(1.5)^{* * a}$ & $10.3(5.9)^{\mathrm{c}}$ \\
\hline & & Buccal $n=10$ & $70.7(12.1)$ & $61.0(13.5)$ & $4.9(1.9)^{\mathrm{a}}$ & $34.1(12.7)^{\mathrm{c}}$ \\
\hline & & Buccal+Lingual $n=10$ & $75.0(13.5)^{\mathrm{b}}$ & $73.3(16.8)^{\mathrm{a}}$ & $4.5(1.8)^{* * *}$ & $22.2(15.9)^{\mathrm{c}}$ \\
\hline \multirow{6}{*}{$\begin{array}{c}13 \\
\text { weeks }\end{array}$} & \multirow{3}{*}{ Titanium } & Lingual $n=10$ & $96.0(2.0)^{c}$ & $94.8(3.3)^{c}$ & $2.2(1.2)^{\mathrm{c}}$ & $3.0(2.6)^{c}$ \\
\hline & & Buccal $n=10$ & $87.9(10.1)^{\mathrm{b}}$ & $78.3(12.7)^{\mathrm{b}}$ & $14.1(11.7)$ & $7.6(8.3)^{c}$ \\
\hline & & Buccal+Lingual $n=10$ & $92.0(8.6)^{c}$ & $86.6(12.8)^{c}$ & $8.1(10.5)^{a}$ & $5.3(6.8)^{c}$ \\
\hline & \multirow{3}{*}{$\begin{array}{c}\text { Ce-TZP } \\
\text { composite }\end{array}$} & Lingual $n=10$ & $94.4(4.4)^{\mathrm{b}}$ & $95.2(3.0)^{\mathrm{b}}$ & $2.4(2.4)^{a}$ & $2.3(1.1)^{\mathrm{c}}$ \\
\hline & & Buccal n=10 & $77.8(14.2)$ & $70.3(16.8)$ & $19.8(15.3)^{\mathrm{a}}$ & $9.9(6.2)^{\mathrm{c}}$ \\
\hline & & Buccal+Lingual $n=10$ & $86.1(13.8)^{\mathrm{b}}$ & $82.8(17.8)^{\mathrm{a}}$ & $11.1(14.4)$ & $6.1(6.0)^{\mathrm{c}}$ \\
\hline
\end{tabular}

Comparison Ce-TZP composite ceramic vs titanium: statistically significant difference at $\mathbf{p}<0.05(*), p<0.01(* *)$ and p<0.001( $\left.{ }^{* * *}\right)$. Comparison 4 weeks vs 13 weeks in each group: statistically significant difference at p<0.05 (a), p<0.01(b) and $\mathrm{p}<0.001(\mathrm{c})$.

- $\quad$ Change over time: intra-group comparison

Between 4 and 13 weeks: at the lingual side, there was a significant increase of the mean BIC values for both groups (Fig. 9a), at the buccal side, there was a significant increase of the mean BIC value for the controlgroup and no significant difference for the test group (Fig. 9b) and when combining buccal+lingual BIC values, there was a significant increase of the mean BIC values in both groups (Fig. 9c, Table 3)

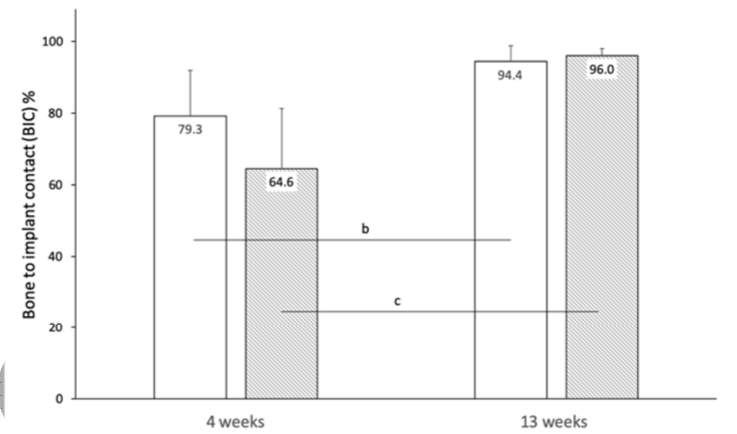

a
aTest acontrol

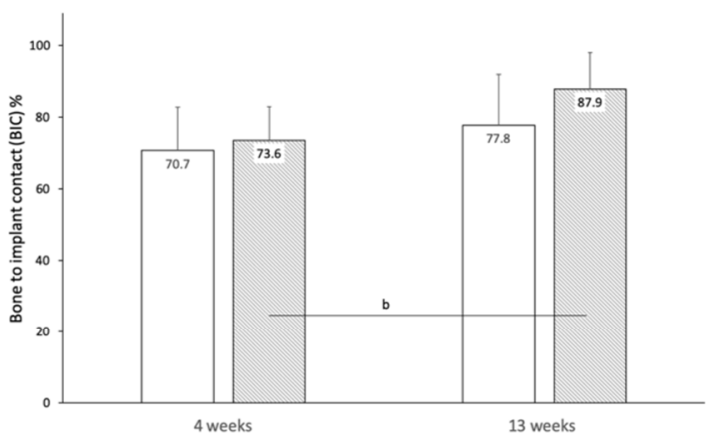

b

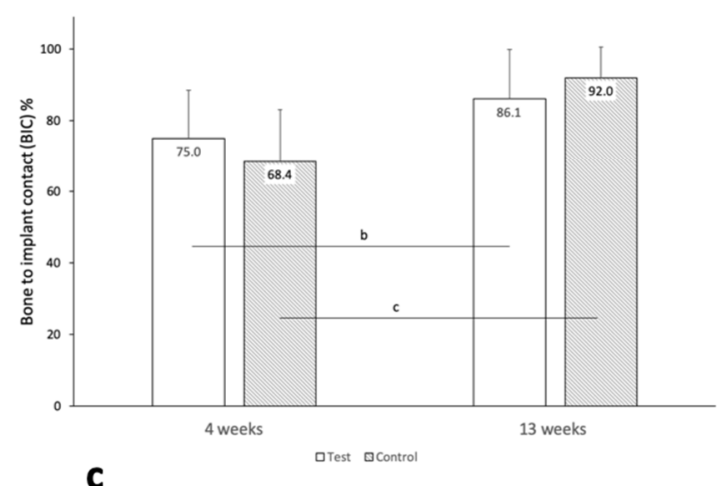


Fig. 9 - Mean ( \pm SD) bone to implant contact on lingual (a), buccal (b) and buccal and lingual (c) sides at 4 and 13 weeks. Comparison 4 weeks vs 13 weeks in each group, statistically significant difference: a $(p<0.05), b(p<0.01)$, and c $(\mathbf{p}<0.001)$

Compared healing: density parameters at lingual and buccal sides in each material group

- $\quad$ Lingual side

Between 4 and 13 weeks, the mean values of bone marrow and fibrous densities decreased and the mean value of bone density increased in both groups (Fig. 10a, Table 3).

- $\quad$ Buccal side

Between 4 and 13 weeks, the mean values of bone marrow density decreased and the mean values fibrous and bone densities increased in both groups (Fig. 10b, Table 3).

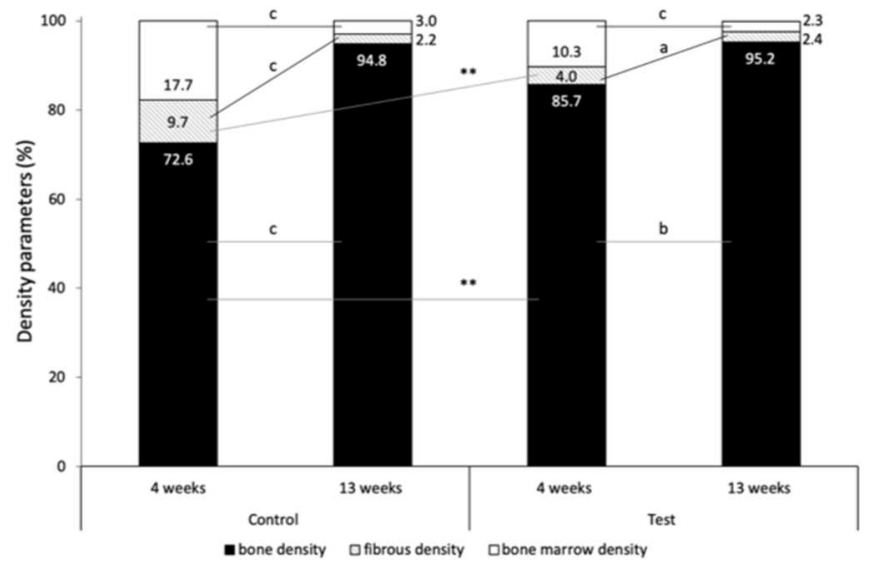

a

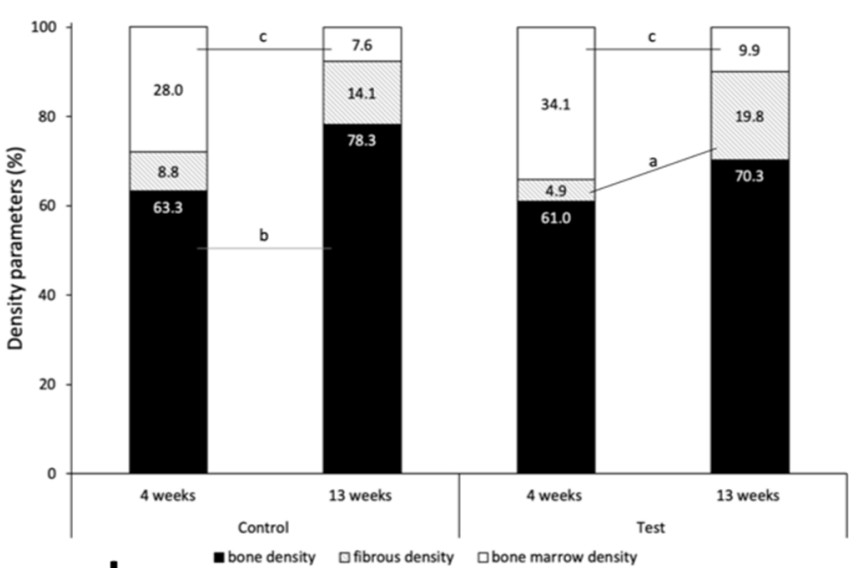

b

Fig. 10 - Mean values of density parameters on lingual (a) and buccal (b) sides at 4 and 13 weeks. Comparison 4 weeks vs 13 weeks in each group, statistically significant difference: a $(p<0.05), b(p<0.01)$ and $c(p<0.001)$. Comparison Ce-TZP composite ceramic vs titanium, statistically significant difference: $*(p<0.05), * *(p<0.01)$ and $* * *(p<0.001)$. 


\section{Discussion}

In the present study, both test and control implants were visible through the gingiva of three dogs after 13 weeks of healing. This behavior, linked to the thinness of the gingival tissues and slightly protruding coronal design, corroborates the aesthetic value of Ce-TZP-based ceramic implants whose color is very close to that of dental roots [18]. The implant design was also characterized by a very narrow diameter $(2.8 \mathrm{~mm})$, guided by the animal model selected and the need to ensure sufficient bone volume around the implants. The breakage of the extra-osseous coronal part of six ceramic implants during the implantation procedure can be attributed to this thin design, in conjunction with the use of a surgical handpiece for implant installation that allowed the application of significant bending forces not reflected in the modest recorded insertion torques. Similar incidents were reported in animal studies by Igarashi et al. in 2015 and 2018 in which respectively two Ce-TZP/ $\mathrm{Al}_{2} \mathrm{O}_{3}$ and one 3Y-TZP implants [19] and two 3Y-TZP implants [20] $3 \mathrm{~mm}$ in diameter broke above the bone surface. Convincing long-term success rates comparable to that of titanium implants are currently available only for implants with diameters of $3.3 \mathrm{~mm}$ or above [21]. The present findings confirm that narrow diameter ceramic implants (below $3 \mathrm{~mm}$ ) with internal connection seem to be too fragile especially for simultaneous application of torque and bending moment. Nevertheless, with regard to the scope of the present study, as the rupture took place far from the bone, the histological sections could be analyzed.

Regarding the biocompatibility of test implants, the local tissue effects of ceramic implants appeared to be minimal compared to titanium control implants. The presence of $\mathrm{Sr}$ does not seem to influence biocompatibility of Ce-TZP-based composites. This result corroborates preliminary results obtained in a rat model with a similar triphasic composite [12] and other results obtained with biphasic composites in the system Ce-TZP/ $/ \mathrm{Al}_{2} \mathrm{O}_{3}[19,20,22]$. Moreover, it should also be noted that in the semi-quantitative evaluation, it was found that some buccal threads were not covered by bone in both groups of implants. This is likely to be explained by the greater bone resorption on the buccal side than on thelingual side at the extracted site due to the surgical trauma inflicted along with flap elevation, root extraction, and implant insertion on a buccal site where the wall bone is narrower and bone resorption could continue after implantation [23].

In the present study, all the mean BIC values obtained were higher than that reported by Albrektsson et al. who defined at $60 \%$ the threshold BIC value required to obtain sufficient bone anchorage over titanium implants [24]. However, as ceramic material tested herein has never been used in investigations of threaded implants, comparisons should be made to other studies that have compared implants of same design and similar periods of healing. These studies $[19,20,25,26]$ also show no-significant difference between ceramic and titanium mean BIC values even if they varied from $51.1 \% \pm 12.4$ [26] to $71.4 \% \pm 17.8$ [25] for ceramic implants after three months of healing. This range of mean BIC values obtained in ceramic implants may therefore be attributed to differences in: tested ceramic material (Y-TZP $[19,20,25], \mathrm{ZrO}_{2}$ [26], Ce-TZP/ $\left./ \mathrm{Al}_{2} \mathrm{O}_{3}[19,20]\right)$, animal models implemented (minipigs [25], pigs [26], dogs [19,20] ) and the site of implantation (tibia [25], maxilla [26], mandible [19,20]).

It is well known that the surface chemistry, treatment and the roughness may affect the osseointegration of the implants. Albrektsson and Wennerberg defined implant roughness [27] and reported that moderately roughened titanium surfaces showed stronger bone response than a smoother surface [27]. The surface morphology seems to be nowadays more important for osseointegration than the surface composition itself [28]. The titanium control implants used in the present study can be classified as moderately rough $(\mathrm{Sa}=1.21 \mu \mathrm{m})$, and the ceramic test implants as minimally rough $(\mathrm{Sa} \sim 0.68 \mu \mathrm{m})$. As the conventional fabrication of zirconia-based devices through machining usually results in relatively smooth surfaces, studies have investigated the effect of different chemical and physical surface modifications of zirconia implants. In 2005, Sennerby et al., using a rabbit model and implants of the same design, prepared two different surface roughness (mean \pm SD: $S a=1.24 \pm 0.19 \mu \mathrm{m}$ and 
$0.93 \pm 0.32 \mu \mathrm{m}$ ) on Y-TZP implants using pore-formers and, although there was no significant difference observed in bone-implant contact, the modified zirconia implants had a resistance to torque forces similar to that of oxidized titanium control implants $(\mathrm{Sa}=1.30 \pm 0.26 \mu \mathrm{m})$ and a four-to-fivefold increase compared with machined zirconia control implants (Sa=0.75 $\pm 0.42 \mu \mathrm{m})[29]$. In 2007, Gahlert et al. using a minipig model compared two different surface treatments of zirconia implants: machined (Sa=0.13 $\mu \mathrm{m}$ ) or sandblasted ( $\mathrm{Sa}=0.56 \mu \mathrm{m}$; with $250 \mu \mathrm{m}$ corundum particles at 5 bars), to titanium implants of the same design and, sandblasted and acid-etched ( $\mathrm{Sa}=1.15 \mu \mathrm{m}$; with $250 \mu \mathrm{m}$ corundum particles at 5 bars). The results for the removal torque test (RTQs) of the $\mathrm{ZrO}_{2}$ sandblasted implants were significantly better than those for $\mathrm{ZrO}_{2}$ machined implants, but at all time periods, SLA implants demonstrated higher mean RTQs than $\mathrm{ZrO}_{2}$ implants [30]. In 2008, Depprich et al. used acid-etched Y-TZP $(\mathrm{Ra}=0.598 \mu \mathrm{m})$ and acid-etched titanium implants of same design $(\mathrm{Ra}=1.77 \mu \mathrm{m})$ without further details as to the surface treatment, and there was no significant difference between the titanium and zirconia implants ( $<<0.05)$ with regards to mean BIC values after 1, 4, or 12 weeks [25]. The lower response to the removal torque test of ceramic implants compared to titanium implants despite absence of significant difference in BIC could be explained by faster bone mineralization on the titanium surface when compared to the zirconia surface [31] and by the lower capacity of adhesion of osteoblasts cells on the zirconia structures in comparison with titanium structures [25]. In general, surface modification leading to an increase of roughness for the titaniumbased but also for the zirconia implants resulted in higher bone-to-implant contacts (BICs) compared to less-rough machined surfaces. In our investigation, SEM characterization and roughness parameters measurements show different surface structures between the titanium-based (control) and the Ce-TZP-based ceramic (test) implants. Nevertheless, there is no significant difference in their biocompatibility and osseointegration capability.

The increase in the roughness of ceramic-based implants induces better osseointegration but can also have a negative impact on the mechanical resistance of the device, due to the brittle behavior of the ceramic. In fact, sandblasting and chemical etching of 3Y-TZP surfaces can potentially introduce strength-limiting surface flaws that affect the damage tolerance of this ceramic.

Although the surface is severely damaged and plastically deformed [32] the flexural strength can also be increased because of the transformation-induced surface strengthening mechanism (induced compressive stresses) [33]. In our study, the mechanical characterization of $\mathrm{Ce}-\mathrm{TZP} / \mathrm{Al}_{2} \mathrm{O}_{3} / \mathrm{SrAl}_{12} \mathrm{O}_{19}$ composites performed in 4P-bending as recommended in 6872(2008) ISO standard revealed relatively high strength, toughness and Weibull modulus. Moreover, blasting and acid etching had no significant impact on the mechanical strength. As regards as the LTD, these Ce-TZP-based triphasic composites show a negligible t-m transformation degree, even after 50 hours of accelerated tests (autoclaving at $134^{\circ} \mathrm{C}-2$ bars) (not shown here, but available in [34]). The newly developed Ce-TZP-based ceramic shows promising characteristics for a future use as more aesthetic and reliable ceramic dental implant.

\section{Conclusions}

Within the limits of this animal investigation, it can be concluded that the new triphasic ceramic composite implants based on CeTZP have a tissue response close to that observed in titanium-based implants and can therefore be considered as biocompatible. Their performances in terms of osseointegration were also comparable. Moreover, the Ce-TZP triphasic composite showed relatively high strength, toughness, Weibull modulus and no aging in aqueous environments. These properties make this ceramic composite quite resistant to processing variations and to surface treatments, like blasting, etching or machining, which are commonly applied in the dental implants manufacturing process and give to it an unneglectable advantage when compared to YTZP dental ceramics. However, further investigations and clinical studies are necessary to evaluate the performances of this new ceramic material in oral implantology. 


\section{Acknowledgements}

The authors thank Philip Robinson for providing the proofreading in English. The members of the SISCERA project consortium are gratefully acknowledged for their assistance in the preparation of the samples and their constant support throughout the project. We would particularly like to thank Ms. Fei Zhang for having carried out all the mechanical characterization of Ce-TZP triphasic ceramics and Ms. Aléthéa Liens for the characterization of implants. The research leading up to these results was undertaken in the framework of the SISCERA project (http://siscera-project.eu) funded by the European Community (H2020FTIPilto-2016, grant agreement no. 737954).

\section{REFERENCES}

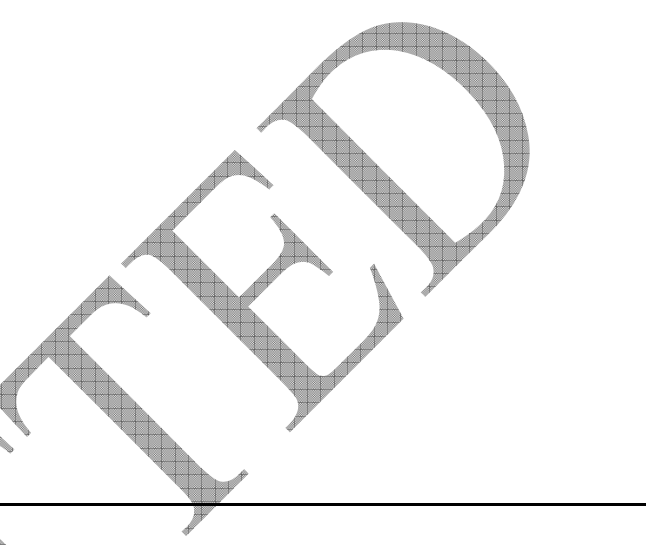

[1] Brånemark PI, Adell R, Breine U, Hansson BO, Lindström J, Ohlsson A. Intra-osseous anchorage of dental prostheses. I.

Experimental studies. Scand J Plast Reconstr Surg 1969;3:81-100. https://doi.org/10.3109/02844316909036699.

[2] Sandhaus S. Material for implants, prostheses and tools (French). Patent N. 1.471.090, P.V.53.006, 1962.

[3] Garvie RC, Hannink RH, Pascoe RT. Ceramic steel? Nature 1975;258:703-4. https://doi.org/10.1038/258703a0.

[4] Chevalier J, Gremillard L, Deville S. Low-Temperature Degradation of Zirconia and Implications for Biomedical Implants. Annual

Review of Materials Research 2007;37:1-32. https://doi.org/10.1146/annurev.matsci.37.052506.084250.

[5] Chevalier J, Loh J, Gremitlard L, Meille S, Adolfson E. Low-temperature degradation in zirconia with a porous surface. Acta

Biomater 2011;7:2986-93. https://doi.org/10.1016/j.actbio.2011.03.006.

[6] Frigan K, Chevalier J, Zhang F, Spies BC. Is a Zirconia Dental Implant Safe When It Is Available on the Market? Ceramics

2019;2:568-77. https://doi.org/10.3390/ceramics2040044.

[7] Gahlert M, Burtscher D, Grunert I, Kniha H, Steinhauser E. Failure analysis of fractured dental zirconia implants. Clinical Oral

Implants Research 2012;23:287-93. https://doi.org/10.1111/j.1600-0501.2011.02206.x.

[8] Osman RB, Swain MV, Atieh M, Ma S, Duncan W. Ceramic implants (Y-TZP): are they a viable alternative to titanium implants 
for the support of overdentures? A randomized clinical trial. Clin Oral Implants Res 2014;25:1366-77. https://doi.org/10.1111/clr.12272.

[9] Roehling S, Woelfler H, Hicklin S, Kniha H, Gahlert M. A Retrospective Clinical Study with Regard to Survival and Success

Rates of Zirconia Implants up to and after 7 Years of Loading. Clin Implant Dent Relat Res 2016;18:545-58.

https://doi.org/10.1111/cid.12323.

[10] Reveron H, Fornabaio M, Palmero P, Fürderer T, Adolfsson E, Lughi V, et al. Towards long lasting zirconia-based composites for dental implants: Transformation induced plasticity and its consequence on ceramic reliability. Acta Biomater 2017;48:423-32. https://doi.org/10.1016/j.actbio.2016.11.040.

[11] Chevalier J, Liens A, Reveron H, Zhang F, Reynaud P, Douillard T, et al. Forty years after the promise of «ceramic steel?»: Zirconia-based composites with a metal-like mechanical behavior. Journal of the American Ceramic Society 2020;103:1482-513. https://doi.org/10.1111/jace.16903.

[12] Altmann B, Karygianni L, Al-Ahmad A, Butz F, Bächle M, Adolfsson E, et al- Implant Materials: Assessment of Novel LongLasting Ceria-Stabilized Zirconia-Based Ceramics with Different Surface Topographies as Implant Materials (Adv. Funct. Mater. 40/2017). Advanced Functional Materials 2017;27. https://doi.org/10.1002/adfm.201770238.

[13] Davies IJ. Confidence limits for Weibull parameters estimated using linear least squares analysis. Journal of the European Ceramic Society 2017;37:5057-64. https://doi.org/10.1016/j.jeurceramsoc.2017.05.051.

[14] Wennerberg A, Albrektsson T. Suggested guidelines for the topographic evaluation of implant surfaces. Int J Oral Maxillofac Implants 2000;15:331-44

[15] Albrektsson T, Wennerberg A. Oral implant surfaces: Part 1--review focusing on topographic and chemical properties of different surfaces and in vivo responses to them. Int J Prosthodont 2004;17:536-43.

[16] Kilkenny C, Browne WJ, Cuthill IC, Emerson M, Altman DG. Improving bioscience research reporting: the ARRIVE guidelines for reporting animal research. PLoS Biol 2010;8:e1000412. https://doi.org/10.1371/journal.pbio.1000412. 
http://www.iso.org/cms/render/live/en/sites/isoorg/contents/data/standard/06/10/61089.html (accessed January 5, 2020).

[18] Jung RE, Sailer I, Hämmerle CHF, Attin T, Schmidlin P. In vitro color changes of soft tissues caused by restorative materials. Int J Periodontics Restorative Dent 2007;27:251-7.

[19] Igarashi K, Nakahara K, Haga-Tsujimura M, Kobayashi E, Watanabe F. Hard and soft tissue responses to three different implant materials in a dog model. Dent Mater J 2015;34:692-701. https://doi.org/10.4012/dmj.2014-361.

[20] Igarashi K, Nakahara K, Kobayashi E, Watanabe F, Haga-Tsujimura M. Hard and soft tissue responses to implant made of three different materials with microgrooved collar in a dog model. Dent Mater J 2018;37:964-72. https://doi.org/10.4012/dmj.2017-197. [21] Bormann K-H, Gellrich N-C, Kniha H, Schild S, Weingart D, Gahlert M. A prospective clinical study to evaluate the performance of zirconium dioxide dental implants in single-tooth edentulous area: 3-year follow-up. BMC Oral Health 2018;18:181. https://doi.org/10.1186/s12903-018-0636-x.

[22] Lopez-Píriz R, Fernández A, Goyos-Ball L, Rivera S, Díaz LA, Fernández-Domínguez M, et al. Performance of a New Al2O3/CeTZP Ceramic Nanocomposite Dental Implant: A Pilot Study in Dogs. Materials (Basel) 2017;10. https://doi.org/10.3390/ma10060614.

[23] Araújo MG, Sukekava F, Wennström JL, Lindhe J. Ridge alterations following implant placement in fresh extraction sockets: an experimental study in the dog. J Clin Periodontol 2005;32:645-52. https://doi.org/10.1111/j.1600-051X.2005.00726.x.

[24] Albrektsson T, Eriksson AR, Friberg B, Lekholm U, Lindahl L, Nevins M, et al. Histologic investigations on 33 retrieved Nobelpharma implants. Clin Mater 1993;12:1-9. https://doi.org/10.1016/0267-6605(93)90021-x.

[25] Depprich R, Zipprïch H, Ommerborn M, Naujoks C, Wiesmann H-P, Kiattavorncharoen S, et al. Osseointegration of zirconia implants compared with titanium: an in vivo study. Head Face Med 2008;4:30. https://doi.org/10.1186/1746-160X-4-30.

[26] Gahlert M, Röhling S, Wieland M, Sprecher CM, Kniha H, Milz S. Osseointegration of zirconia and titanium dental implants: a histological and histomorphometrical study in the maxilla of pigs. Clin Oral Implants Res 2009;20:1247-53.

https://doi.org/10.1111/j.1600-0501.2009.01734.x.

[27] Albrektsson T, Wennerberg A. Oral implant surfaces: Part 2--review focusing on clinical knowledge of different surfaces. Int J 
Prosthodont 2004;17:544-64.

[28] Hanawa T. Zirconia versus titanium in dentistry: A review. Dent Mater J 2020;39:24-36. https://doi.org/10.4012/dmj.2019-172.

[29] Sennerby L, Dasmah A, Larsson B, Iverhed M. Bone tissue responses to surface-modified zirconia implants: A histomorphometric and removal torque study in the rabbit. Clin Implant Dent Relat Res 2005;7 Suppl 1:S13-20. https://doi.org/10.1111/j.1708-

8208.2005.tb00070.x.

[30] Gahlert M, Gudehus T, Eichhorn S, Steinhauser E, Kniha H, Erhardt W. Biomechanical and histomorphometric comparison between zirconia implants with varying surface textures and a titanium implant in the maxilla of miniature pigs. Clin Oral Implants Res 2007;18:662-8. https://doi.org/10.1111/j.1600-0501.2007.01401.x.

[31] Gehrke SA, Prados-Frutos JC, Prados-Privado M, Calvo-Guirado JL, Aramburú Júnior J, Pérez-Díaz L, et al. Biomechanical and Histological Analysis of Titanium (Machined and Treated Surface) Versus Zirconia Implant Materials: An In Vivo Animal Study. Materials (Basel) 2019;12. https://doi.org/10.3390/ma12060856.

[32] Cotič J, Jevnikar P, Kocjan A, Kosmač T. Complexity of the relationships between the sintering-temperature-dependent grain size, airborne-particle abrasion, ageing and strength of 3Y-TZP ceramics. Dent Mater 2016;32:510-8. https://doi.org/10.1016/j.dental.2015.12.004.

[33] Kosmac T, Oblak C, Jevnikar P, Funduk N, Marion L. The effect of surface grinding and sandblasting on flexural strength and reliability of Y-TZP zirconia ceramic. Dent Mater 1999;15:426-33. https://doi.org/10.1016/s0109-5641(99)00070-6.

[34] Palmero P, Fornabaio M, Montanaro L, Reveron H, Esnouf C, Chevalier J. Towards long lasting zirconia-based composites for dental implants. Part I: innovative synthesis, microstructural characterization and in vitro stability. Biomaterials 2015;50:38-46. 